\title{
Route Selection of Multimodal Transport Based on China Railway Transportation
}

\author{
Hui Zhang $\left(\mathbb{D},{ }^{1,2,3,4}\right.$ Yao Li $\mathbb{D},{ }^{1}$ Qingpeng Zhang $\left(\mathbb{D},{ }^{5}\right.$ and Dingjun Chen $\mathbb{D}^{1,2,3}$ \\ ${ }^{1}$ School of Transportation and Logistics, Southwest Jiaotong University, Chengdu 610031, China \\ ${ }^{2}$ National and Local Joint Engineering Laboratory of Comprehensive Intelligent Transportation, Southwest Jiaotong University, \\ Chengdu 610031, China \\ ${ }^{3}$ National Engineering Laboratory of Integrated Transportation Big Data Application Technology, Chengdu 610031, China \\ ${ }^{4}$ State Laboratory of Rail Transit (Under Preparation), Beijing, China \\ ${ }^{5}$ School of Data Science, City University of Hong Kong, Kowloon Tong, Hong Kong
}

Correspondence should be addressed to Dingjun Chen; chen-dingjun@163.com

Received 4 April 2021; Revised 25 May 2021; Accepted 30 June 2021; Published 12 July 2021

Academic Editor: Chi-Hua Chen

Copyright (c) 2021 Hui Zhang et al. This is an open access article distributed under the Creative Commons Attribution License, which permits unrestricted use, distribution, and reproduction in any medium, provided the original work is properly cited.

The advantage of multimodal transport is that it can deliver the goods to their destination in a reasonable combination of transport modes while ensuring security and punctuality. Multimodal transportation can effectively reduce logistics costs, improve logistics efficiency, and reduce environmental pollution. In the process of multimodal transportation, due to the interference of natural factors (weather, terrain, etc.) and some special human factors, it may have different degrees of impact on the transportation time and transportation safety of different transportation modes. Therefore, when choosing a transportation method, it is necessary to consider the transportation time and transportation safety under the interference. However, the current research on multimodal transport has not considered the impact of external interference on transportation time and transportation safety. Compared with other modes of transportation, external interference has a relatively small impact on railway transportation. Railways can safely deliver goods to their destinations on time. Under the background of China's huge railway network and advanced heavy-duty technology, this paper establishes a multimodal transport route selection model for considering railway as the core, introduces time penalty cost and damage compensation cost, and takes the lowest comprehensive transportation cost as the model objective under the premise of considering transportation reliability and transportation safety. Finally, taking a multimodal transport network in China as an example, an improved ant colony algorithm is used to solve the model and the results verify the rationality of the model.

\section{Introduction}

Multimodal transport [1] is a mode of cargo transportation through the connection and transshipment of two or more transportation modes (such as railway transportation, water transportation, road transportation, and air transportation) to complete the transportation process. At present, China is at an important stage of economic structural transformation and upgrading, and the freight transportation market is facing historical changes. The establishment of a new and efficient logistics channel based on multimodal transport can connect China's inland economy and coastal economy, which is the key to the transformation and upgrading of
China's economic structure. This shows that promoting the development of multimodal transport is of great significance. According to statistics, in 2017, China's multimodal freight volume was 1.368 billion tons, accounting for $2.9 \%$ of the total freight volume of the society. According to the "Notice on Further Encouraging Multimodal Transport Work" by 18 departments including the Ministry of Transport, China's multimodal transport freight volume will reach 3.02 billion tons in 2020 . By then, the scale of multimodal transport freight will account for $6 \%$ of the total freight volume\%, the proportion is still low. The multimodal transport freight volume accounts for a small proportion of the whole society's freight volume, which is caused by the 
incomplete construction of China's current integrated transportation system. With the increasing market requirements, more efficient, more resource-efficient, and more intensive transportation services are required to achieve a rational division of labor and organic linkage of various modes of transportation, and to give full play to the overall efficiency and effectiveness of the integrated transportation system. However, at present, all kinds of transportation modes in the integrated transportation system are self-contained, which are only physically connected through hubs, and the limited joint command is carry out under the emergency condition. There are some problems, such as imperfect mechanism, market segmentation, prominent transport structural contradictions, weak hub service capacity, poor operational coordination, and low safety and service level, which make the great potential of integrated transportation not fully released. It affects the full play of the efficiency of various modes of transport and the public's sense of gain (quoted: the 13th Five-Year Plan of Integrated Transport Services), which cannot meet the economic, reliable, and efficient freight demand.

Compared with other modes of transportation, railway transportation is more economical and environmentally friendly, and the advantages of transportation reliability and transportation security are more obvious. At the same time, railway transportation as a participant of multimodal transportation has good transportation conditions. Data show that in 2018, the national railways completed 3.19 billion tons of cargo shipments, a year-onyear increase of $9.3 \%$, which increased transportation by 272 million tons. With the formation of the "four vertical and four horizontals" networks of high-speed railways and the promotion of the "eight vertical and eight horizontals" high-speed rail network, the operating mileage of the railway reached 131,000 kilometers, of which the operating mileage of the high-speed railway was 31,000 kilometers. It is concluded that China has a huge railway network, and the operating mileage of railways covers the entire country. Although railways have a nationwide road network and huge transportation capacity, they have not been fully utilized. In 2018, China's highway freight volume was 39.568 billion tons, accounting for $76.79 \%$ of the country's total freight; China's railway freight volume was 4.022 billion tons, accounting for $7.81 \%$ of the country's total freight. So, making full use of railway capacity has become a key goal for China to promote the development of multimodal transport. In response to this situation, relevant Chinese departments have formulated a "road to rail transportation" policy, and railway management is included in the Ministry of Transport. These policies make it possible for railways to play a backbone role in the integrated transportation system. So, it is urgent to study the cooperative operation theory and key technologies of the railway-based integrated transportation system. This paper will deeply study the optimization of multimodal transport path selection with railway transportation as the main body, and realize the rational division of labor and coordinated development of various transportation modes.
In multimodal transport network design, Christine and Sabine [2] conducted a scenario-based assessment of the future position of intermodal transport within Belgiumbased case studies and discussed service network design models for consolidation-based freight transport systems; Demir et al. [3] studied the design problem of green multimodal transport network with uncertain transportation time [4-6] and established a stochastic optimization model that can generate robust transportation plans according to different objectives (cost, time, and carbon emissions); Wang and Meng [7] considered a discrete multimodal transport network design problem and decided whether the network planner needs to establish or extend a path to minimize operating costs. Cheng and Jin [8] constructed the multimodal transportation route selection models with congestion considered under different low-carbon polices; Demir et al. [3] introduced a green intermodal service network design problem with travel time uncertainty (GISND-TTU) for combined offline intermodal routing decisions of multiple commodities. In the path optimization of multimodal transport, many scholars have made in-depth research based on different aspects. Fazayeli et al. [9] studied the problem of multimodal transport path optimization under fuzzy demand, established a mixed-integer fuzzy mathematical model, and solved it by genetic algorithms [10]; Fotuhi studied the optimization problem of multimodal transport path with uncertain network topology [11]; Idri et al. [12] introduced a search method for the shortest path algorithm in parallel distributed architecture to solve the path optimization problem of dynamic multimodal transport network with time dependence [13, 14]; Liu et al. [15] established a super transportation network to predict the generalized cost of multimodal transportation, which provides technical support for the comprehensive transportation planning. Li constructed a route selection model for cargo multimodal transportation and used an improved ant colony algorithm to be solved. Tian et al. [16] explored the influence of multiple time windows on the route selection of fresh products and designed genetic algorithms to solve it. Zhu et al. established an evaluation model of container multimodal transport based on BP neural network and solved the optimal path. Russo et al. [17] research object is a variable of the operating cycle of a rail transit terminal, the variable considered is the overall average time of the terminal operation cycle relative to the number of trucks and vehicles entering the terminal, which solved the problem of the efficiency of public rail transport; Abderrahman et al. [18] proposed a robust optimization model for the transportation cost of multimodal freight and the uncertainty of network terminal capacity [19]; Liu et al. [20] in the context of global containerized transportation of soybeans considers the transportation and purchase costs of soybeans, establishes a multimodal transport network model, and optimizes the soybean transportation path [21]; Verma et al. [22] designed a dual-objective mixed-integer linear programming model for the problem of joint transportation path selection for dangerous goods with minimum transportation costs and risks of transportation and designed a modelsolving algorithm based on taboo search; Toumazi and 
Kwon [23] introduced the conditional value-at-risk (CVaR) theory and built a CVaR-based road transport route optimization model for dangerous goods under a time-varying network [16, 24]. The optimal dangerous goods road transport can be selected based on the risk aversion of decision makers' path; Sun and Long [25] took into account the customer's need for timeliness of transportation when planning the multimodal transport path [26] and obtained the optimal solution through Pareto optimality.

At present, the research on multimodal transport does not consider the influence of natural factors such as weather, terrain, and some special human factors on the transport [15]. In actual transportation, these factors may lead to the delay [27] of transport time, and even the occurrence of dangerous accidents [28] and damage of goods. At this time, the cost and time of the original optimal path will change, and the optimal path will change accordingly [29, 30]. The multimodal transport research based on railways mostly focuses on transportation policy, and there are few research projects on path selection. Therefore, this paper establishes a multimodal transport route selection model based on railway transportation, introduces time penalty cost and damage compensation cost, considering the transportation reliability and transportation safety factors in the transportation process, aiming at the minimum transportation cost, and finds the optimal path that is in line with reality.

\section{Construction of Multimodal Transport Model}

2.1. Problem Description. The route selection problem of multimodal transportation mainly based on railway transportation can be described as follows: In a multimodal transport network $G=(V, A), V$ is the node set of networks $G$ and $A$ is the path set of networks $G$. The shipper requires that a batch of goods be transported from the origination $o \in A$ to the destination $d \in A$. The carrier needs to consider the reliability and safety of the transportation routes between the origination and destination, so as to select the transportation route and mode that can reach the destination within the time specified by the shipper and ensure that the goods are intact.

2.2. Variable Definitions. The notation of parameters and variables is shown in Table 1.

\section{Objective Functions}

The goal of multimodal transport is to maximize the transport efficiency and spend as little cost and time as possible to make the goods arrive at the destination safely. Multimodal transport is the combined transport of multiple modes of transport, and transportation cost and transportation time for different modes of transport are different. Therefore, when calculating the model target, it is necessary to choose a transportation mode with lower transportation cost and shorter transportation time. However, in the actual transportation process, the transportation cost and transportation time of various transportation modes are not fixed. They will change with the interference of natural factors and some special human factors. Different transportation modes have different antijamming capabilities, and transportation costs and transportation time have different degrees of variation. For example, in foggy weather conditions, various modes of transportation will be affected, but rail transportation will be less affected, and the transportation time will be slightly extended; the speed of road transportation will be greatly reduced, and safety accidents may occur due to operational errors, not only the safety of life is involved but also the transported goods will be damaged. The carrier will have to compensate the shipper for losses, and the transportation cost and transportation time will increase significantly.

When the transportation cost and transportation time are dynamically changing, it will dynamically affect the choice of transportation mode. Therefore, the model built in this paper focuses on the change of transportation cost and transportation time during transportation. In this paper, the degree of change in transportation time is expressed as transportation reliability, and the time penalty cost is established. The degree of change in transportation cost is expressed as transportation safety, and the damage compensation cost is established. At the same time, considering the global low-carbon environmental protection at the current stage, low-carbon transportation is the top priority for the country. Multimodal operation is an emerging efficient transportation mode. It is also necessary to reduce carbon emissions as much as possible in response to national calls. Therefore, this paper will start from the cost, energy conservation, time, transport reliability, and transport safety to build a path optimization model with the minimum comprehensive cost:

$$
\min Z=\omega_{1}\left(C_{1}+C_{2}+C_{3}\right)+\omega_{2} C_{4}+\omega_{3} C_{5} .
$$

In the formula, $Z$ is the comprehensive transport cost; $C_{1}, C_{2}, C_{3}, C_{4}$, and $C_{5}$ are transportation cost, transit cost, carbon emission cost, time penalty cost, and damage compensation cost, respectively; and $\omega_{1}, \omega_{2}$, and $\omega_{3}$ are the weights of each cost in the objective function.

3.1. Transportation Cost and Transit Cost. The cost of freight transportation between adjacent nodes is the transportation cost, and the cost of replacing the transportation mode inside the transferable node is the transit cost:

$$
\begin{aligned}
& \min C_{1}=\sum_{i \in M} \sum_{j \in M} \sum_{s \in S} Q c_{i j}^{s} d_{i j}^{s} x_{i j}^{s}, \\
& \min C_{2}=\sum_{i \in M} \sum_{s \in S} \sum_{s^{\prime} \in S} Q c_{i}^{s s^{\prime}} y_{i}^{s s^{\prime}} .
\end{aligned}
$$

3.2. Carbon Emission Cost. In order to develop a low-carbon economy, countries all over the world have studied energy conservation and emission reduction and proposed a carbon tax scheme. Carbon tax is a tax imposed on carbon emissions 
TABLE 1: Subscripts and parameters used in mathematical formulations.

$\begin{aligned} & \text { Symbol } \\ & M\end{aligned}$
$K$
$S$
$Q$ $\begin{array}{r}\text { Network node set (all nodes including the start node and the end node) } \\ \text { Transportable node set }\end{array}$

and is an important means of limiting carbon emissions. The calculation formula of carbon tax is as follows:

$$
\theta=\sum_{0}^{t} D_{t}(1+\lambda)^{-t}
$$

In the formula, $D_{t}$ is the damage value of thet-year caused by the unit carbon emissions and $\lambda$ is the discount rate. In fact, the carbon tax is not levied as high as possible. If the carbon tax is higher, it will restrict the economic development of the country. If the carbon tax is too low, it will not play a good role in energy conservation and emission reduction. According to the research of experts and scholars in China, the proposal of the Ministry of environmental protection for carbon tax is $20 \$ /$ ton. Therefore, in this paper, the carbon tax is assumed to be $20 \$ /$ ton and $0.02 \$ /$ $\mathrm{kg}$. The carbon emission cost is the product of carbon emissions and carbon tax:

$$
\min C_{3}=\theta \times \sum_{i \in M} \sum_{j \in M} \sum_{s \in S} Q E_{S} d_{i j}^{s} x_{i j}^{s} .
$$

3.3. Transportation Reliability and Time Penalty Cost. Transport reliability herein refers to the on-time arrival rate from the starting point to the end point within a specified time using either mode of transport. In the actual transportation process, various modes of transportation will be affected by natural factors and some special human factors, resulting in delays in transportation, such as traffic jams caused by road conditions; trains will stop and wait during the meeting, and long ramps will have a great impact on the running speed and so on. Transportation delay will prolong the transportation time and may exceed the delivery time limit, so if the model does not take into account the transportation reliability factors, the obtained optimal path will lose its significance in the actual transportation context. In order to quantify the impact of transportation reliability on transportation time, this paper defines the time delay coefficient: taking into account the complex influencing factors between adjacent nodes and taking values within $0-1$ so that the transportation time of the section is extended linearly on the basis of the original transportation time, as shown in Figure 1.

In the diagram, $t$ represents the transportation time between two nodes without considering the delay, and $\mu$ is the time delay coefficient. When $\mu=0$, there is no time delay in the transportation process of goods, and the actual transportation time of goods is the initial transportation time $t$. When $\mu=1$, there is time delay in the transportation process of goods, and the actual transportation time is the initial time $t$ plus the delay time quantified as $t$. When $\mu$ is between 0 and 1, the delay time of goods is related to the delay coefficient, defining that the delay time has a linear relationship with the delay coefficient.

A certain penalty is imposed for transportation schemes that exceed the time limit. In order to quantify the impact of the time limit of delivery on the transportation plan selection, the time penalty function is introduced in this paper. Taking into account the changes in the psychological state of the consignee while waiting for the delivery of the goods, this paper adopts the fuzzy convenience function to express and defines 2 hours as a state change gradient in case of exceeding the arrival time limit and assigns different degrees of punishment to different state gradients, as shown in Figure 2 . 


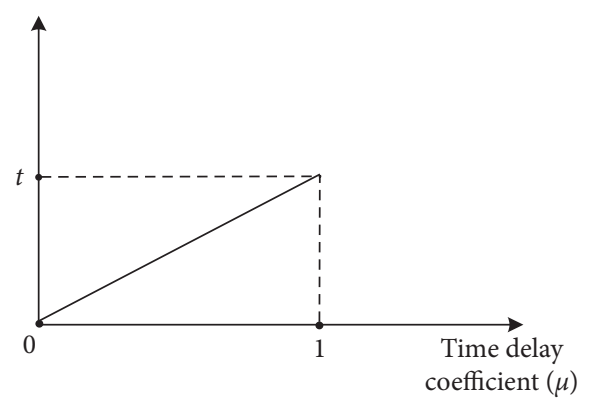

FIgURE 1: Time delay function.

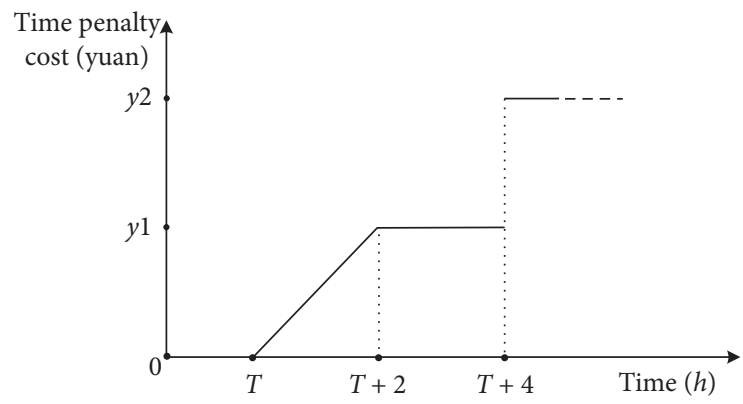

FIgURE 2: Time penalty cost function.

$$
\begin{aligned}
& X=\sum_{i \in M} \sum_{j \in M} \sum_{s \in S}\left(1+\mu_{i j}^{s}\right) \frac{d_{i j}^{s}}{V_{S}} x_{i j}^{s}+\sum_{i \in M} \sum_{s \in S} \sum_{s^{\prime} \in S} T_{i}^{s s^{\prime}} y_{i}^{s s^{\prime}}, \\
& \min C_{4}= \begin{cases}0, & X \leq T, \\
\frac{y_{1}}{2}(X-T), & T \leq X \leq T+2, \\
y_{1}, & T+2 \leq X \leq T+4, \\
y_{2}, & T+4 \leq X .\end{cases}
\end{aligned}
$$

Formula (5) is the transportation time calculation formula for any transportation scheme: the first part is the sum of transportation time and delay time, and the second part is the transit time of the transportable node. Formula (6) is the time penalty cost calculation formula, when the transportation time is from $T$ to $T+2$, the penalty function is a linear increasing function; when the time is from $T+2$ to $T+4$, the penalty function is a constant $\left(y_{1}\right)$; when the transportation time exceeds $T+4$, the penalty function is a constant $\left(y_{2}\right)$.

\subsection{Transportation Safety and Damage Compensation Costs.} Transport safety in this paper refers to the value loss rate of goods transported during transportation from the starting point to the end point. The influencing factors mainly include road conditions and traffic management status, vehicle technical performance, and warranty quality, as well as the driver's operating skill level and responsibility. If a safety accident occurs during transportation, the transportation goods will be damaged. The carrier shall compensate the consignor for the corresponding loss according to the degree of damage to the goods because the liability of the accident is that the carrier has not planned the transportation route. If the safety factors in the transportation process are not considered when optimizing the route, the final result is likely to lose more. In order to facilitate the calculation, this paper assumes that the degree of damage to the goods is determined by the severity of the accident when a safety accident occurs during transportation. That is to say, if the severity of the accident is relatively low, the goods may only be partially damaged rather than completely damaged. In order to quantify the impact of the severity of the accident on the damage of the goods, this paper proposes and defines the accident damage coefficient: the value is within $0-1$, and the change from 0 to 1 indicates that the degree of damage of the goods increases gradually and the amount of compensation required by the carrier increases gradually, and the amount of compensation is based on the value of the goods:

$$
\min C_{5}=\sum_{i \in M} \sum_{j \in M} \sum_{s \in S} \psi_{i j}^{s} x_{i j}^{s} Q \pi .
$$

\section{Constraints}

\subsection{Transportation Process Constraint}

$$
\begin{array}{ll}
\sum_{s \in S} x_{i j}^{s} \leq 1, & \forall(i, j) \in M, \\
\sum_{s, s^{\prime} \in S} y_{i}^{s s^{\prime}} \leq 1, & \forall i \in K, \\
x_{h i}^{s}+x_{i j}^{s^{\prime}} \geq 2 y_{i}^{s s^{\prime}}, & \forall h, i, j \in M, \forall s, s^{\prime} \in S, \\
\sum_{s \in S} q_{h i}^{s}=\sum_{s \in S} q_{i j}^{s}, \quad \forall(h, i, j) \in M .
\end{array}
$$

Constraint (8) makes sure that only one mode of transport can be selected between any adjacent nodes. Constraint (9) ensures that only one transit can occur in any transit node. Constraint (10) guarantees the continuity of transportation mode during transit. Constraint (11) is the flow equilibrium constraint of nodes in the network.

\subsection{Carbon Emission Constraint}

$$
\sum_{i \in M} \sum_{j \in M} \sum_{s \in S} Q E_{S} d_{i j}^{s} x_{i j}^{s}=C d,
$$

$$
C d \leq E
$$

Constraint (12) is the formula of total carbon emissions, and for this paper, which is a known constant. Constraint (13) ensures that the transportation plan meets the total carbon emission limit.

\section{Multiobjective Ant Colony Algorithm}

The ant colony algorithm is a simulation evolution algorithm proposed by DORIGO. It is an effective means to solve the 
multiobjective optimization problem in discrete space; however, the basic ant colony algorithm has the problems of slow running efficiency, premature convergence, and easy to fall into a local optimal solution. This paper combines the solution requirements of the multimodal transport path selection model. In order to improve the effectiveness of the algorithm, the basic algorithm is improved accordingly.

5.1. Node Transition Probability. Although the objective function of the model in this paper is the total cost value in the transportation process, the time penalty cost is determined by the length of the transportation time. The model target expectation cost and time are as small as possible, so in the improved ant colony algorithm, a cost heuristic function and a time heuristic function need to be set at the same time. It will mainly rely on the influence of path pheromone concentration, cost heuristic experience, and time heuristic experience when choosing to reach the node:

$$
\begin{aligned}
& P_{i j}^{k}(t)= \begin{cases}\frac{\tau_{i j}^{\alpha}(t) \eta_{i j}^{\beta}(t) \theta_{i j}^{\lambda}(t)}{\sum_{s \in \text { allowed }_{k}} \tau_{i s}^{\alpha}(t) \eta_{i s}^{\beta}(t) \theta_{i s}^{\lambda}(t)}, & j \in \text { allowed }_{k}, \\
0 & \text { otherwise, }\end{cases} \\
& \eta_{i j}=\frac{1}{\sum_{s \in S} Q c_{i j}^{s}\left(d_{i j}^{s} / V_{S}\right) x_{i j}^{s}+\sum_{s \in S} \theta Q E_{S} d_{i j}^{s} x_{i j}^{s}+\sum_{s \in S} \psi_{i j}^{s} x_{i j}^{s} Q \pi+\sum_{s \in S} \sum_{s^{\prime} \in S} Q c_{i}^{s s^{\prime}} y_{i}^{s s^{\prime}},}, \\
& \theta_{i j}=\frac{1}{\sum_{s \in S}\left(d_{i j}^{s} / V_{S}\right) x_{i j}^{s}+\sum_{s \in S} \sum_{s^{\prime} \in S} T_{i}^{s s^{\prime}} y_{i}^{s s^{\prime}} .}
\end{aligned}
$$

Formula (14) is the node transition probability formula in the multiobjective ant colony algorithm, where $\alpha$ is the information heuristic factor, $\beta$ is the cost expectation heuristic factor, $\lambda$ is the time expectation heuristic factor, and $\tau_{i j}$ is the pheromone concentration on path $(i, j)$. Formula (15) is a cost heuristic function, whose value is inversely proportional to the sum of transportation cost, carbon emission cost, and damage compensation cost on path 1 and transit cost of inode. Formula (16) is a time heuristic function, whose value is inversely proportional to the sum of transportation time on path $(i, j)$ and transit time of inode.
5.2. Pheromone Update Rule. The principle of the positive feedback mechanism of ant colony algorithm is based on the continuous update of pheromone, so the pheromone update rule is the key to solving the problem of speed and accuracy of ant colony algorithm. This paper considers the basic idea of ant colony algorithm with elite strategy: at the end of each cycle, additional pheromone enhancement is given to the optimal solution found in this cycle in order to make the optimal solution found so far more attractive to the ants in the next cycle. The pheromone is updated according to the following formula:

$$
\begin{aligned}
& \tau_{i j}(t+n)=(1-\rho) \tau_{i j}(t)+\Delta \tau_{i j}(t, t+n)+\Delta \tau_{i j}^{*}(t, t+n), \\
& \Delta \tau_{i j}^{*}(t, t+n)= \begin{cases}\sigma \cdot \frac{q}{C^{*}}, & \text { If path }(i, j) \text { is part of the optimal path in this cycle, } \\
0, & \text { otherwise. }\end{cases}
\end{aligned}
$$

Formula (17) is the pheromone concentration on path $(i, j)$ at time $t+n$, and $\rho$ is the pheromone global volatilization coefficient, $\Delta \tau_{i j}(t, t+n)$ is the amount of pheromone increase on path $(i, j)$ from time $t$ to time $t+n$. Formula (18) is the amount of pheromone increase on path $(i, j)$ caused by elite ants from time $t$ to time $t+n, q$ is the pheromone intensity, $\sigma$ is the number of elite ants, and $C^{*}$ is the optimal solution value found in this cycle.
Using the elite strategy can make the ant system find a better solution through fewer cycles, and the solution speed is faster. However, after using the elite strategy, the attractiveness of the current optimal solution increases, so that the search process is concentrated near the optimal solution found so far, thereby preventing further searches for a better solution. The problem of premature convergence is more likely to occur. In order to maintain the selection pressure, this paper extends the concept of ranking in genetic 
algorithms to the elite mechanism and calculates $\Delta \tau_{i j}(t, t+n)$ by a weighted method. After completing a cycle, the ants are sorted according to the size of the target value found in the cycle, and the ant's contribution to the pheromone update is considered to be inversely proportional to the target value of the path the ant passes. The contribution of the ant to the pheromone update is weighted according to the ranking of the ant $(\xi)$. In order to ensure the speed of the solution while expanding the solution space, it is considered that only the top $(\mathrm{m} / 4)$ ants can contribute to the pheromone update, and the amount of pheromone obtained by the path it passes is proportional to the ant's ranking. $\Delta \tau_{i j}(t, t+n)$ is calculated as follows:

$$
\begin{aligned}
\Delta \tau_{i j}(t, t+n) & =\sum_{\mu=1}^{(m / 4)} \Delta \tau_{i j}^{\xi}(t, t+n), \\
\Delta \tau_{i j}^{\xi}(t, t+n) & = \begin{cases}\frac{C_{a v}-C_{\xi}}{C_{a v}-C^{*}} \cdot \frac{q}{C_{\xi}}, & \text { if ant } \xi \text { passes the path }(i, j), \\
0, & \text { otherwise. }\end{cases}
\end{aligned}
$$

Formula (20) represents the contribution of the ant $\xi$ to the increase in the amount of pheromone on the path $(i, j), \xi$ is the ranking of the ants, $C_{a v}$ represents the average value of the target of this cycle, and $C_{\xi}$ represents the target value found by the ant $\xi$.

5.3. Pheromone Limit Interval. Although the aforementioned improved pheromone update rule can solve the problems of solution speed and precocious convergence, it is easy to fall into the dilemma of local optimization and the algorithm stops searching. Therefore, in this paper, the idea of MMAS is introduced in the process of pheromone updating. The upper and lower limits are imposed on the pheromone, and the limiting interval of the pheromone is set to $\left[\tau_{\min }, \tau_{\max }\right]$. When performing pheromone update according to the aforementioned pheromone update rules, the following is obtained:

(1) If $\tau_{i j}(t)>\tau_{\max }$ occurs, $\tau_{i j}(t)=\tau_{\max }$ is required

(2) If $\tau_{i j}(t)<\tau_{\min }$ occurs, $\tau_{i j}(t)=\tau_{\min }$ is required

This can effectively avoid that the amount of pheromone on one path is much larger than the rest, so that all ants are concentrated on the same path, resulting in a local optimal situation.

5.4. Algorithm Flowchart. In summary, the multiobjective ant colony algorithm flowchart is as shown in Figure 3.

\section{Case Study}

Take China's multimodal transport network with 10 cities as an example, it involves 10 cities, the origination is Chengdu and the destination is Shanghai, as shown in Table 2. Since there are many inland cities in this multimodal transport network and the water transport is poor, we considered three transport modes: road, railway, and air in this case. The node cities in the multimodal transport network are numbered sequentially, and the schematic diagram of the multimodal transport network of this case is made accordingly, as shown in Figure 4.

This case involves three transportation modes. We need to consider how to clearly express the ant's choice behavior for transportation mode when using the ant colony algorithm. Therefore, we have simply dealt with the multimodal transport network. Each transport node is expanded into multiple virtual subnodes according to the number of transport modes. For example, transfer node 3 is extended to railway node, highway node, and airport node. In the processed network diagram, there is a transport problem among multiple subnodes of the same node. But it is not the ant to select the next arrival node, that is to say, there is no sequence between the subnodes, which is the same level parallel relationship. The network deformation diagram is shown in Figure 5.

The transportation mileage, time delay coefficient, and accident damage coefficient of different transportation modes among node cities are shown in Table 3. The time delay coefficient is given according to the road condition of each node city and the different characteristics of transportation mode. The accident damage coefficient is given by the traffic management status of each node city and the technical performance of each transportation mode.

The requirements for freight volume, transportation time limit, and unit value of goods by freight forwarders and the requirements for carbon emission limit by government officials are shown in Table 4.

The unit transit cost and unit transit time between different modes of transport are shown in Table 5.

The transportation cost, average speed, and carbon emission factors of each transportation mode are shown in Table 6.

6.1. Results' Analysis. The multiobjective ant colony algorithm is used to write the algorithm code on the MATLAB R2014a platform. The algorithm parameters are set as follows: $\lambda=3, \alpha=1, \beta=3, q=2, \rho=0.9$, the number of ants is 100, and the number of iterations is 200, $y_{1}=10000, y_{2}=20000$. Taking the weight of the objective function as $1 / 3$ as an example, the optimal path of multimodal transport is Chengdu to Chongqing to Wuhan to Hefei to Nanjing, and the total cost is 331750 . To explore the results of multimodal transport route optimization considering different cost factors, the weight of each objective function is assigned in turn, and the following conclusions are drawn in this paper.

6.2. Objective Weight Sensitivity Analysis. In order to explore the multimodal path optimization results when considering different cost factors, this paper analyzes the sensitivity of the objective function weights as shown in Table 7 and draws the following conclusions:

In Figure 6, Experiment $(1,5)$ and $(2,4)$ are compared, it is found that when the weight of damage compensation cost 


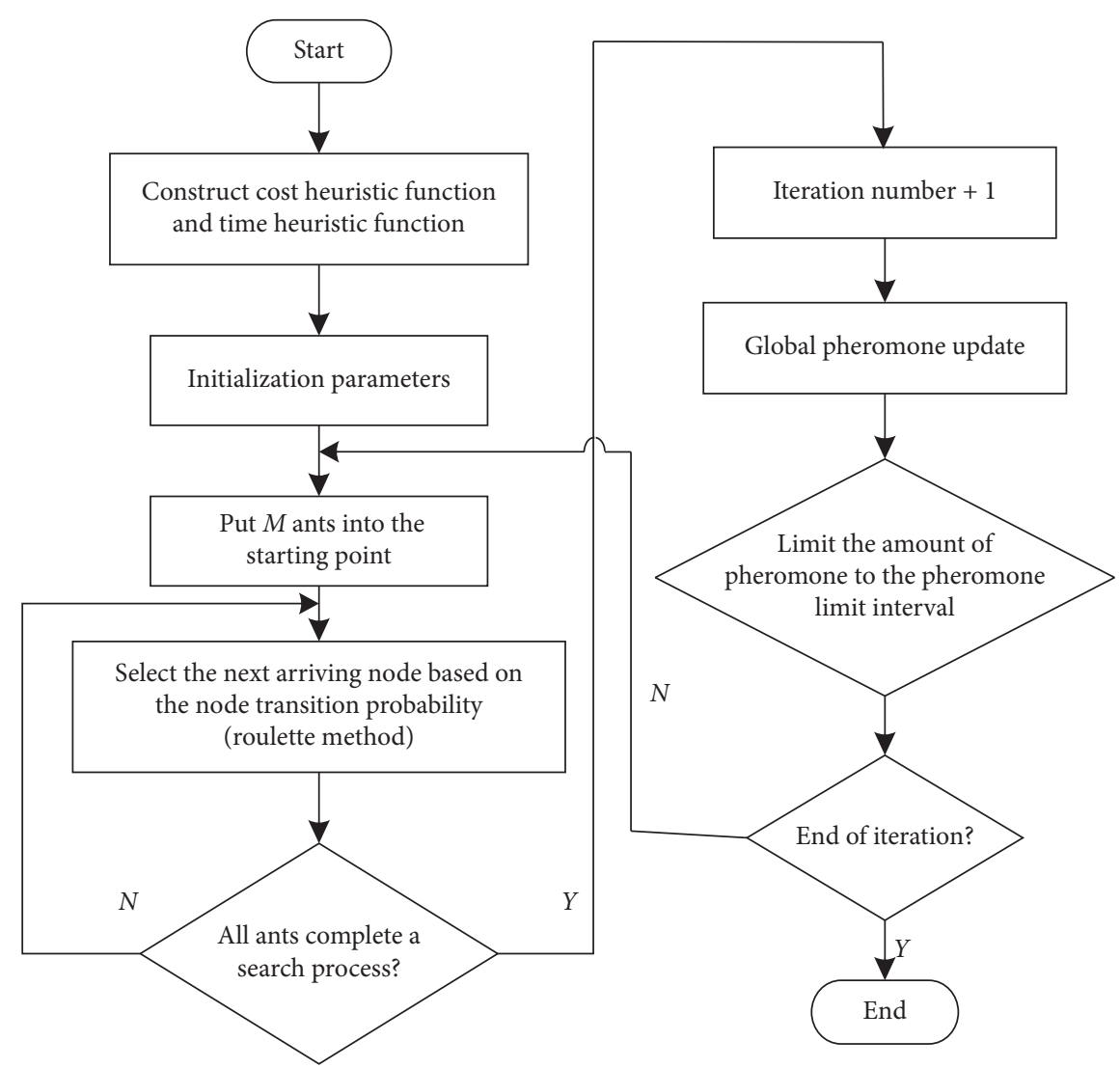

FIGURE 3: Multiobjective ant colony algorithm flowchart.

TABle 2: Node city number.

\begin{tabular}{lccccc}
\hline Number & 1 & 2 & 3 & 4 & 5 \\
\hline Name of node city & Chengdu & Xi'an & Chongqing & Guiyang & 9 \\
Number & 6 & 7 & Zhengzhou & 10 \\
Name of node city & Wuhan & Changsha & Hefei & Nanchang & Nanjing \\
\hline
\end{tabular}

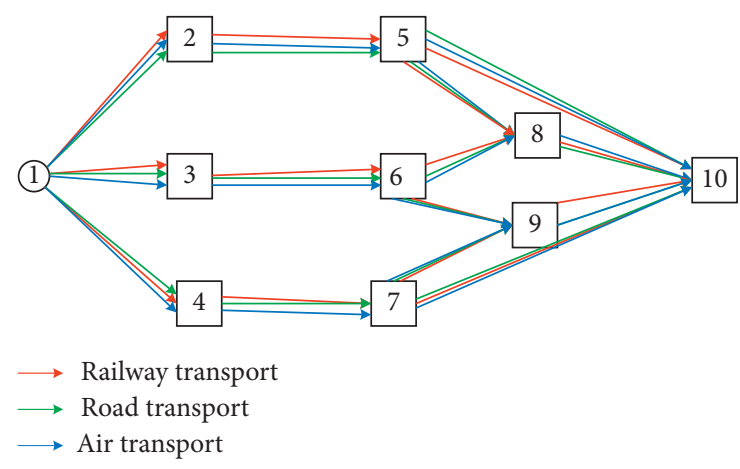

Figure 4: Multimodal network diagram.

is the same, and the weight of the sum of transportation cost, transshipment cost, and carbon emission cost is high, the optimal path is the railway-road combined transportation. The railway-road combined transport pays more attention to the cost of transport. It pays more attention to the size of the cost incurred in the transportation process. When the weight
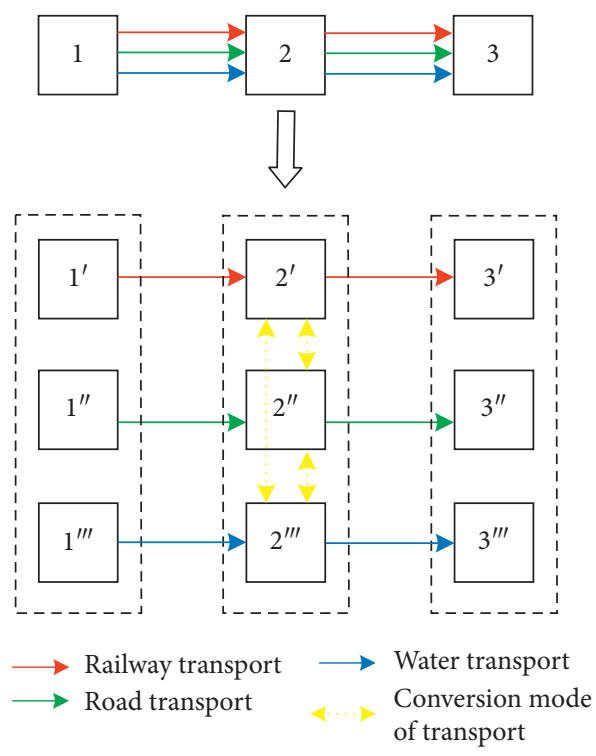

FIGURE 5: Transit node deformation. 
TABLE 3: Transport distance and time delay coefficient between node pairs.

\begin{tabular}{|c|c|c|c|c|c|c|c|}
\hline Adjacent node & $(1,2)$ & $(1,3)$ & $(1,4)$ & $(2,5)$ & $(3,6)$ & $(4,7)$ & $(5,8)$ \\
\hline Railway mileage $(\mathrm{km})$ & 842 & 504 & 967 & 511 & 1233 & 956 & 645 \\
\hline Time delay coefficient & 0.19 & 0.08 & 0.12 & 0.21 & 0.07 & 0.16 & 0.10 \\
\hline Accident damage coefficient & 0.04 & 0.01 & 0.06 & 0.08 & 0.02 & 0.07 & 0.03 \\
\hline Highway mileage $(\mathrm{km})$ & 719 & 326 & 721 & 479 & 898 & 872 & 673 \\
\hline Time delay coefficient & 0.14 & 0.11 & 0.09 & 0.17 & 0.07 & 0.13 & 0.19 \\
\hline Accident damage coefficient & 0.09 & 0.02 & 0.08 & 0.05 & 0.02 & 0.08 & 0.13 \\
\hline Waterway mileage $(\mathrm{km})$ & 612 & 270 & 521 & 434 & 752 & 645 & 465 \\
\hline Time delay coefficient & 0.16 & 0.12 & 0.12 & 0.19 & 0.09 & 0.14 & 0.15 \\
\hline Accident damage coefficient & 0.15 & 0.02 & 0.12 & 0.07 & 0.08 & 0.05 & 0.06 \\
\hline Adjacent node & $(5,10)$ & $(6,8)$ & $(6,9)$ & $(7,9)$ & $(7,10)$ & $(8,10)$ & $(9,10)$ \\
\hline Railway mileage (km) & 695 & 1181 & 365 & 418 & 1200 & 312 & 838 \\
\hline Time delay coefficient & 0.18 & 0.11 & 0.15 & 0.13 & 0.14 & 0.10 & 0.17 \\
\hline Accident damage coefficient & 0.05 & 0.03 & 0.06 & 0.04 & 0.05 & 0.05 & 0.07 \\
\hline Highway mileage $(\mathrm{km})$ & 698 & 495 & 370 & 399 & 921 & 178 & 603 \\
\hline Time delay coefficient & 0.15 & 0.17 & 0.10 & 0.16 & 0.20 & 0.12 & 0.18 \\
\hline Accident damage coefficient & 0.06 & 0.05 & 0.18 & 0.05 & 0.14 & 0.02 & 0.09 \\
\hline Waterway mileage $(\mathrm{km})$ & 564 & 316 & 264 & 290 & 705 & 145 & 468 \\
\hline Time delay coefficient & 0.19 & 0.13 & 0.16 & 0.18 & 0.17 & 0.11 & 0.15 \\
\hline Accident damage coefficient & 0.04 & 0.05 & 0.04 & 0.05 & 0.05 & 0.01 & 0.17 \\
\hline
\end{tabular}

Table 4: Parameter selection.

\begin{tabular}{lcccc}
\hline Parameter & Freight $(\mathrm{t})$ & Transportation time limit $(\mathrm{h})$ & Carbon emission limit $(\mathrm{kg})$ & Value of goods $(\mathrm{yuan} / \mathrm{t})$ \\
\hline Value & 100 & 45 & 10000 & 1000 \\
\hline
\end{tabular}

TABle 5: Transit cost and transit time of transit node.

\begin{tabular}{lcccccc}
\hline \multirow{2}{*}{ Transit } & \multicolumn{2}{c}{ Rail transport } & \multicolumn{2}{c}{ Road transport } & \multicolumn{2}{c}{ Air transport } \\
& Cost $(\mathrm{yuan} / \mathrm{t})$ & Time $(\mathrm{h} / \mathrm{t})$ & Cost $(\mathrm{yuan} / \mathrm{t})$ & Time $(\mathrm{h} / \mathrm{t})$ & Cost $(\mathrm{yuan} / \mathrm{t})$ & 12 \\
\hline Rail transport & - & - & 12 & 0.01 & 0.02 \\
Road transport & 10 & 0.01 & - & - & 0.03 & 15 \\
Air transport & 12 & 0.02 & 15 & - & - \\
\hline
\end{tabular}

Note. The unit of transit cost is yuan/t; and the unit of transit time is $\mathrm{h} / \mathrm{t}$.

TABLE 6: Transport mode parameters.

\begin{tabular}{lccc}
\hline Mode of transport & Transportation cost $(\mathrm{yuan} / \mathrm{t} \cdot \mathrm{km})$ & Average speed $(\mathrm{km} / \mathrm{h})$ & Unit carbon $\mathrm{emissions} /(\mathrm{kg} / \mathrm{t} \cdot \mathrm{km})$ \\
\hline Highway & 1.5 & 100 & 0.12 \\
Railway & 1 & 75 & 0.025 \\
Waterway & 5 & 600 & 1.05 \\
\hline
\end{tabular}

TABLE 7: Weight assignment experiment number.

\begin{tabular}{|c|c|c|c|c|c|c|c|c|c|c|c|c|c|c|c|}
\hline Number & & 1 & & & 2 & & & 3 & & & 4 & & & 5 & \\
\hline Weight assignment & $\begin{array}{l}\omega_{1} \\
0.7\end{array}$ & $\begin{array}{l}\omega_{2} \\
0.1\end{array}$ & $\begin{array}{l}\omega_{3} \\
0.2\end{array}$ & $\begin{array}{l}\omega_{1} \\
0.5\end{array}$ & $\begin{array}{l}\omega_{2} \\
0.2\end{array}$ & $\begin{array}{l}\omega_{3} \\
0.3\end{array}$ & $\begin{array}{c}\omega_{1} \\
1 / 3\end{array}$ & $\begin{array}{c}\omega_{2} \\
1 / 3\end{array}$ & $\begin{array}{c}\omega_{3} \\
1 / 3\end{array}$ & $\begin{array}{l}\omega_{1} \\
0.2\end{array}$ & $\begin{array}{l}\omega_{2} \\
0.5\end{array}$ & $\begin{array}{l}\omega_{3} \\
0.3\end{array}$ & $\begin{array}{l}\omega_{1} \\
0.1\end{array}$ & $\begin{array}{l}\omega_{2} \\
0.7\end{array}$ & $\begin{array}{l}\omega_{3} \\
0.2\end{array}$ \\
\hline
\end{tabular}

of time penalty cost is high, the optimal route is mainly airrailway combined transportation, and more attention is paid to the length of transportation time. As the carbon emission factor of road transportation is relatively high and the transport time of railway transportation is relatively long, the carbon emission cost of Experiment 1 and 2 is relatively high and the time penalty cost is relatively high. Due to the poor safety of air transport compared with other modes of transport, the cost of compensation for damages in Experiment 4 and 5 is relatively high.

Generally speaking, in the comprehensive consideration of cost, time, energy saving, and transportation safety, whether it is air-railway combined transport or road-railway combined transport, railway occupies a large proportion, which also proves that multimodal transport based on railway transportation can indeed maximize the transport benefits. 


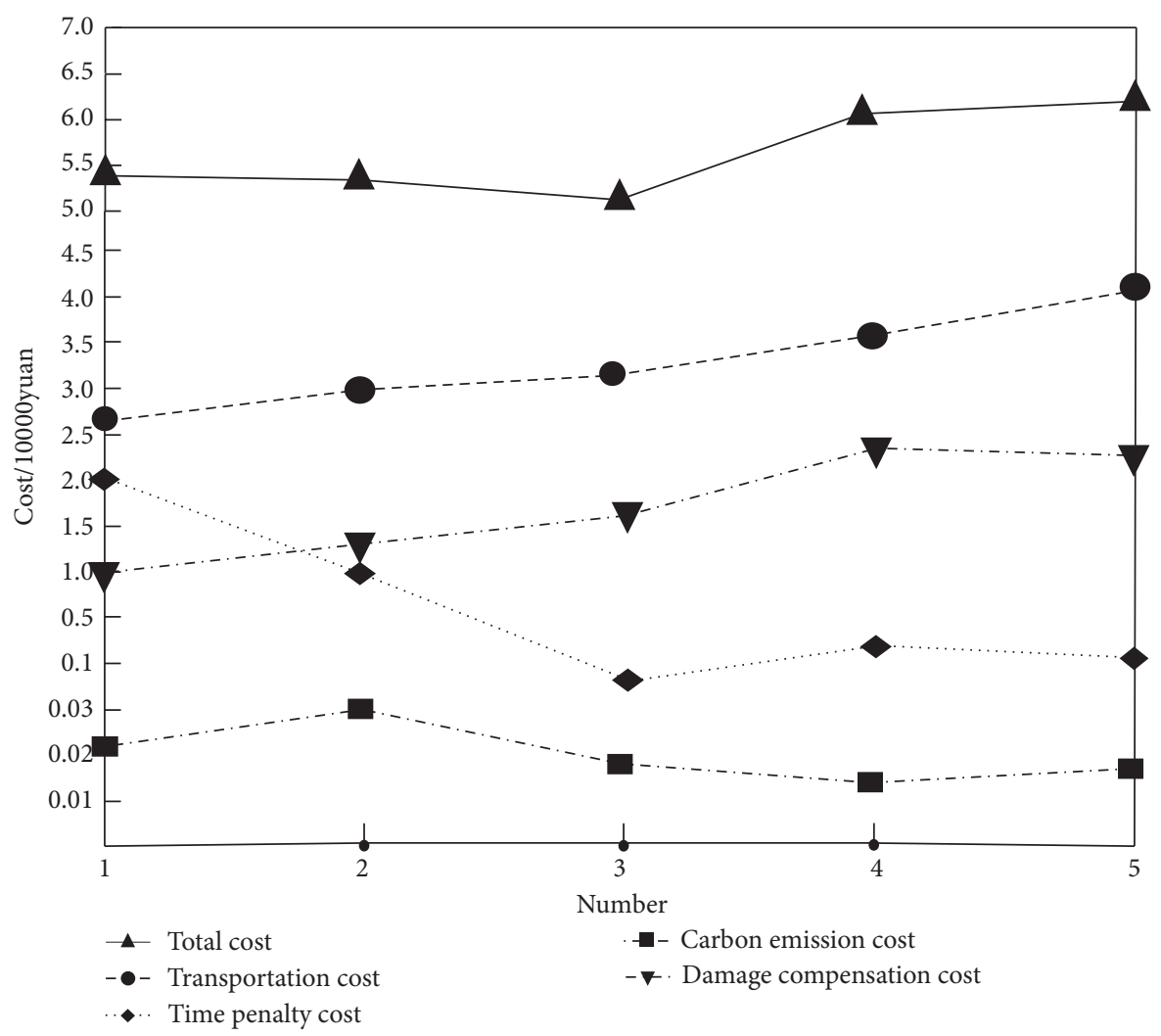

FIgURE 6: Sensitivity analysis of cost weights.

TABLE 8: Comparison of total cost of optimal path.

\begin{tabular}{lccc}
\hline Optimal path & Transportation mode & $\begin{array}{c}\text { Total cost (transport stability and transport safety } \\
\text { are not considered) }\end{array}$ & $\begin{array}{c}\text { Total cost (transportation stability and } \\
\text { safety are considered) }\end{array}$ \\
\hline 1-3-7-9-10 & $\begin{array}{c}\text { Railway-highway-highway- } \\
\text { highway }\end{array}$ & $\$ 312689$ & $\$ 349854$ \\
\hline
\end{tabular}

6.3. Analysis of Transportation Reliability and Transportation Safety. In order to explore the practicability of the model, all cost weights are set to $1 / 3$, and the ant colony algorithm is used to solve the problem without considering the transportation reliability and transportation safety.

From Table 8, it can be concluded that the highway has a higher proportion in the optimal path solved without considering the transportation reliability and transportation safety. However, the transportation reliability and transportation safety of road transportation are poor, so the total cost of this optimal path in the model constructed in this paper exceeds the total cost of multimodal transportation optimal path based on railway transportation. This result is also in line with China's policy of transitioning from road transport to railway transport because railway transport is more stable and safer, and it can transport goods safely and in a timely manner. With the continuous development of other modes of transportation, in the future, China or other countries may have a multimodal transport mode based on road transport or other modes of transport. However, transportation reliability and transportation safety are the factors that must be considered in the multimodal path optimization problem; therefore, the model established in this paper is still applicable to the route selection and optimization of other transportation modes.

\section{Conclusions}

The paper analyzes and demonstrates the important position of railway transportation in multimodal transport and establishes a multimodal transport route selection model based on railway transportation. In view of some problems that often occur during transportation, this paper focuses on transportation reliability and transportation safety, introduces time penalty cost and damage compensation cost, and defines time delay coefficient and accident damage coefficient, respectively. Taking a multimodal transport network in China as a case, and the network is transformed according to the characteristics of the ant colony algorithm. Sensitivity analysis of cost weights proves that the multimodal transport based on railway transportation can maximize transportation efficiency. The analysis of transportation reliability and transportation safety shows that the model constructed in this paper has strong practicability and wide application range. 


\section{Data Availability}

The data used to support the findings of this study are available from the corresponding author upon request.

\section{Conflicts of Interest}

The authors declare that they have no conflicts of interest.

\section{Acknowledgments}

This research was supported by the National Key R\&D Program of China (2017YFB1200702), National Natural Science Foundation of China (Project nos. 52072314 and 71971182), Sichuan Science and Technology Program (Project nos. 2020YJ0268, 2020YJ0256, 2021YFQ0001, and 2021YFH0175), Chengdu Science and Technology Plan Research Program (Project nos. 2019-YF05-01493-SN, 2020RK00-00036-ZF, and 2020-RK00-00035-ZF), Science and Technology Plan of China Railway Corporation (Project nos. P2018T001 and 2019KY10), the Natural Science Foundation of Zhejiang Province, China (LQ18G030012), and the Humanities and Social Sciences Fund of Ministry of Education, China (18YJC630190).

\section{References}

[1] Y. M. Bontekoning, C. Macharis, and J. J. Trip, "Is a new applied transportation research field emerging? A review of intermodal rail-truck freight transport literature," Transportation Research Part A: Policy and Practice, vol. 38, no. 1, pp. 1-34, 2003.

[2] T. Christine and L. Sabine, "Scenario-based analysis for intermodal transport in the context of service network design models," Transportation research interdisciplinary perspectives, vol. 2, 2019.

[3] E. Demir, W. Burgholzer, M. Hrušovský, E. Arıkan, W. Jammernegg, and T. V. Woensel, "A green intermodal service network design problem with travel time uncertainty," Transportation Research Part B: Methodological, vol. 93, no. 7, pp. 789-807, 2016.

[4] M. L. Chen, X. J. Zhao, X. G. Deng et al., "Multimodal transport path optimization under uncertain conditions," Journal of Highway and Transportation Research and Development, vol. 38, no. 1, pp. 143-150, 2021.

[5] M. Ghazanfari, L. Sara, R. Daphne, and Q. Liron, "Commuter behavior under travel time uncertainty," Performance Evaluation, vol. 148, 2021.

[6] M. Hrusovsky, E. Demir, W. Jammernegg, and W. Van, "Hybrid simulation and optimization approach for green intermodal transportation problem with travel time uncertainty," International Journal of Flexible Manufacturing Systems, vol. 30, no. 3, pp. 486-516, 2018.

[7] X. Wang and Q. Meng, "Discrete intermodal freight transportation network design with route choice behavior of intermodal operators," Transportation Research Part B: Methodological, vol. 95, no. 1, pp. 76-104, 2017.

[8] X. Q. Cheng and C. Jin, "Route selection problem in multimodal transportation with traffic congestion considered under low-carbon policies," Operations Research and Management Science, vol. 28, no. 4, pp. 67-77, 2019.

[9] S. Fazayeli, A. Eydi, and I. N. Kamalabadi, "Location-routing problem in multimodal transportation network with time windows and fuzzy demands: presenting a two-part genetic algorithm," Computers \& Industrial Engineering, vol. 119, no. 5, pp. 233-246, 2018.

[10] H. Li and L. Su, "Multimodal transport path optimization model and algorithm considering carbon emission multitask," The Journal of Supercomputing, vol. 76, no. 12, pp. 9355-9373, 2020.

[11] J. Wan and S. Wei, "Multi-objective multimodal transportation path selection based on hybrid algorithm," Journal of Tianjin University, vol. 52, no. 3, pp. 285-292, 2019.

[12] A. Idri, M. Oukarfi, A. Boulmakoul, K. Zeitouni, and A. Masri, "A distributed approach for shortest path algorithm in dynamic multimodal transportation networks," Transportation Research Procedia, vol. 27, no. 12, pp. 294-300, 2017.

[13] C.-H. Chen, "An arrival time prediction method for bus system," IEEE Internet of Things Journal, vol. 5, no. 5, pp. 4231-4232, 2018.

[14] N. Koohathongsumrit and W. Meethom, "Route selection in multimodal transportation networks: a hybrid multiple criteria decision-making approach," Journal Of Industrial And Production Engineering, vol. 38, no. 3, pp. 171-185, 2021.

[15] S. Liu, C. Yin, D. Chen, H. Lv, and Q. Zhang, "Cascading failure in multiple critical infrastructure interdependent networks of syncretic railway system," IEEE Transactions on Intelligent Transportation Systems, vol. 2021, pp. 1-14, 2021.

[16] Z. Tian, G. Sun, D. Chen, Z. Qiu, and Y. Ma, "Method for determining the valid travel route of railways based on generalised cost under the syncretic railway network," Journal of Advanced Transportation, vol. 2020, no. 2, 12 pages, 2020.

[17] F. Russo and U. Sansone, "The terminal cycle time in road-rail combined transport," Wit Transactions on Ecology \& the Environment, vol. 186, pp. 875-886, 2014.

[18] A. Abderrahman, A. Ahmede, and B. Jaouad, "Robust optimization of the intermodal freight transport problem: modeling and solving with an efficient hybrid approach," Journal of Computational Science, vol. 30, no. 1, pp. 127-142, 2019.

[19] Y. Jiang and X. C. Zhang, "Transport plan design for rail-truck intermodal transportation," Journal of Transporation Systems Engineering \& Information Technology, vol. 18, no. 6, pp. 222-228, 2018.

[20] X. Liu, Y. Bai, and J. Chen, "An intermodal transportation geospatial network modeling for containerized soybean shipping," Journal of Ocean Engineering and Science, vol. 2, no. 2, pp. 143-153, 2017.

[21] D. Chen, S. Ni, C. A. Xu, and X. Jiang, "Optimizing the draft passenger train timetable based on node importance in a railway network," Transportation Letters, vol. 11, no. 1, pp. 20-32, 2019.

[22] M. Verma, V. Verter, and N. Zufferey, "A bi-objective model for planning and managing rail-truck intermodal transportation of hazardous materials," Transportation Research Part E: Logistics and Transportation Review, vol. 48, no. 1, pp. 132-149, 2011.

[23] I. Toumazis and C. Kwon, "Routing hazardous materials on time-dependent networks using conditional value-at-risk," Transportation Research Part C: Emerging Technologies, vol. 37, no. 3, pp. 73-92, 2013.

[24] Z. Xu, Q. Zhang, D. Chen, and Y. He, "Characterizing the connectivity of railway networks," IEEE Transactions on Intelligent Transportation Systems, vol. 21, no. 4, pp. 1491-1502, 2020.

[25] Y. Sun and M. Lang, "Bi-objective optimization for multimodal transportation routing planning problem based on 
Pareto optimality," Journal of Industrial Engineering and Management, vol. 8, no. 3, pp. 1195-1217, 2015.

[26] C.-H. Chen, F.-J. Hwang, and H.-Y. Kung, "Travel time prediction system based on data clustering for waste collection vehicles," IEICE Transactions on Information and Systems, vol. 102, no. 7, pp. 1374-1383, 2019.

[27] Z. Elisabeth and R. V. Gloria, "Optimized allocation of straddle carriers to reduce overall delays at multimodal container terminals," Flexible Services and Manufacturing Journal, vol. 27, no. 2-3, pp. 300-330, 2015.

[28] S. Bret and B. Kendon, "Environmental, public health, and safety assessment of fuel pipelines and other freight transportation modes," Applied Energy, vol. 171, pp. 266-276, 2016.

[29] T. Yang, X. Peng, D. Chen, F. Yang, and M. Muneeb Abid, "Research on trans-region integrated traffic emergency dispatching technology based on multi-agent," Journal of Intelligent \& Fuzzy Systems, vol. 385, no. 5, pp. 5763-5774, 2020.

[30] H. Y. Luo, J. Yang, and X. Nan, "Path and transport mode selection in multimodal transportation with time window," in Proceedings of the 3rd IEEE Advanced Information Technology, Electronic and Automation Control Conference (IAEAC), pp. 162-166, Chongqing, China, 2018. 